\title{
Evolução do uso e cobertura do solo no município de São Francisco do Sul - Estado de Santa Catarina
}

\author{
Evolution of land use in the municipality of São francisco do Sul - Santa Catarina State \\ JOÃO PEDRO SANTOS PAZ ${ }^{1}$; CELSO VOOS VIEIRA ${ }^{1}$ \\ ${ }^{1}$ Universidade da Região de Joinville - UNIVILLE, Santa Catarina - joaopedro.paz@outlook.com, celso.v@univille.br
}

\begin{abstract}
Resumo
No contexto das mudanças globais dinâmicas e aceleradas do século XXI, o conhecimento sobre o uso e a cobertura do solo representam ferramentas importantes para o monitoramento e planejamento urbanístico e ambiental. Este trabalho apresentou o diagnóstico histórico evolutivo comparativo do uso e cobertura do solo do município de São Francisco do Sul/SC e de suas áreas de restrição ambiental. Na elaboração do estudo foram utilizadas imagens orbitais dos satélites Landsat-5 e Landsat-8. Para a classificação das imagens utilizou-se o ArcGis 10.2.2 e foram identificadas oito classes de uso e ocupação do solo: água, manguezal, área urbanizada, vegetação em estágio inicial, solo exposto, vegetação em estágio médio / avançado, gramínea e silvicultura. $\mathrm{O}$ estudo da evolução de uso e cobertura do solo demonstrou um aumento considerável nas áreas urbanizadas no município e uma intensa diminuição de áreas de solo exposto, que foram gradualmente substituídas por vegetação em estágio inicial. Destaca-se ainda a constatação de uma alta taxa de regeneração de áreas degradadas no interior de Áreas de Preservação Permanente e no Parque Estadual Acaraí. Por fim foi identificado que ao longo do período estudado houve um aumento de áreas vegetadas no município, mesmo com a avanço das áreas urbanizadas.
\end{abstract}

Palavras-chave: Sensoriamento remoto; geoprocessamento; área de preservação permanente.

\begin{abstract}
In the context of the dynamic and accelerated global changes of the 21st century, knowledge about land use and land cover are important tools for urbanistic and environmental monitoring and planning. This paper presented the comparative evolutionary historic diagnostic of land use and land cover in the municipality of São Francisco do Sul/SC and in its areas with environmental restrictions. In preparing the study, orbital images obtained by the Landsat-5 and Landsat-8 satellites were used. ArcGis 10.2.2 was used for the classification of the images and eight classes of land use and occupation were identified: water, mangrove, urban area, early stage vegetation, exposed soil, medium/advanced stage vegetation, grass and forestry. The study of the evolution of land use showed a considerable increase in urban areas in the municipality and a high rate of regeneration of degraded areas within the Permanent Preservation Areas and in the Acarai State Park. Finally, it was identified that throughout the studied period there was an increase of vegetated areas in the county, even with the advance of the urbanized areas.
\end{abstract}

Keywords: Remote sensing; geoprocessing; area of permanent preservation.

\section{Introdução}

No debate sobre o desenvolvimento sustentável ganha importância especial a necessidade de garantir de forma integrada a qualidade de vida diante das questões ambientais, sociais e econômicas. No contexto das mudanças globais dinâmicas e aceleradas do século XXI, o estudo e o conhecimento sobre o uso e a cobertura do solo representam informações importantes no fornecimento de subsídios para o monitoramento e planejamento ambiental.

Impactos ambientais provenientes de desmatamentos, perda da biodiversidade, mudanças climáticas, altos índices de urbanização e transformações rurais apresentaram crescimento significativo nas últimas décadas, de acordo com o Instituto Brasileiro de Geografia e Estatística - IBGE (IBGE, 2013). Desta forma, surge a necessidade de estudos que abordem as formas de apropriação destes espaços territoriais no sentido de disciplinar as atividades potencialmente nocivas ao meio ambiente e de promover formas adequadas de utilização dos espaços em concordância com suas capacidades de uso. A utilização de geotecnologias na análise multitemporal permite mapear as transformações ocorridas no processo de uso e ocupação do solo ao longo das últimas décadas (Pinto \& Garcia, 2005; Menezes \& Almeida, 2012).

$\mathrm{O}$ uso de imagens orbitais possibilita o estudo e o monitoramento tanto de fenômenos naturais dinâmicos do meio ambiente (erosão do solo, inundações, entre outros) como dos fenômenos antrópicos. Estes fenômenos impressos na paisagem são registrados nas imagens produtos do sensoriamento remoto, que 
possibilitam identificar, calcular e monitorar o crescimento de áreas desmatadas, áreas impermeabilizadas, assim como identificar áreas susceptíveis a processos erosivos (Amaral \& Rios, 2012).

No intuito de monitorar e minimizar os problemas ambientais, os Sistemas de Informações Geográficas (SIGs), aliados às técnicas de sensoriamento remoto e geoprocessamento apresentam grande potencialidade (Rosa, 2009). Estes recursos permitem o armazenamento e a manipulação de um grande número de dados e informações, bem como a representação cartográfica dessas variáveis, possibilitando o planejamento e orientação à tomada de decisão (Zanata et al. 2012), assim como economia de recursos e de tempo (Simão \& Moraes, 2009). Estas manipulações permitem ainda agregar dados de diferentes fontes (imagens de satélite, cartas topográficas, mapas geológicos e modelos numéricos.) em diferentes escalas de forma integrada (Veiga \& Xavier-Da-Silva, 2004).

A presente pesquisa analisou as alterações ocorridas no uso e cobertura de solo do município de São Francisco do Sul durante três cenários $(1986,2000$ e 2015). O trabalho apresenta ainda um diagnóstico de intervenções antrópicas nas áreas de restrições ambientais do munícipio em questão, podendo assim servir de ferramenta para futuros estudos e prognósticos de impactos ambientais no município.

\section{2. Área de Estudo}

O município de São Francisco do Sul foi escolhido como o objeto de estudo da presente pesquisa, em virtude da relevância histórica, socioeconômica e ambiental. Historicamente o município é a terceira cidade mais antiga do Brasil, com a presença de inúmeros sítios arqueológicos e monumentos que compõem o patrimônio urbanístico e arquitetônico nacional (IPHAN, 2016) (Figura 1). Sua importância socioeconômica está fundamentada nas atividades portuárias, de pesca e turismo na região, aliadas à sua importância ambiental, devido à presença da Baia Babitonga e de diversos ecossistemas ameaçados. De acordo com Rodrigues et al. (2000) encontram-se estabelecidos nas margens da Baía Babitonga: Joinville caracterizado como o maior polo industrial do Estado de Santa Catarina, o porto de São Francisco do Sul, o transporte de petróleo, assim como várias comunidades de pescadores artesanais e catadores de caranguejo, exercendo sua pressão no uso de solo e impactos ambientais específicos.
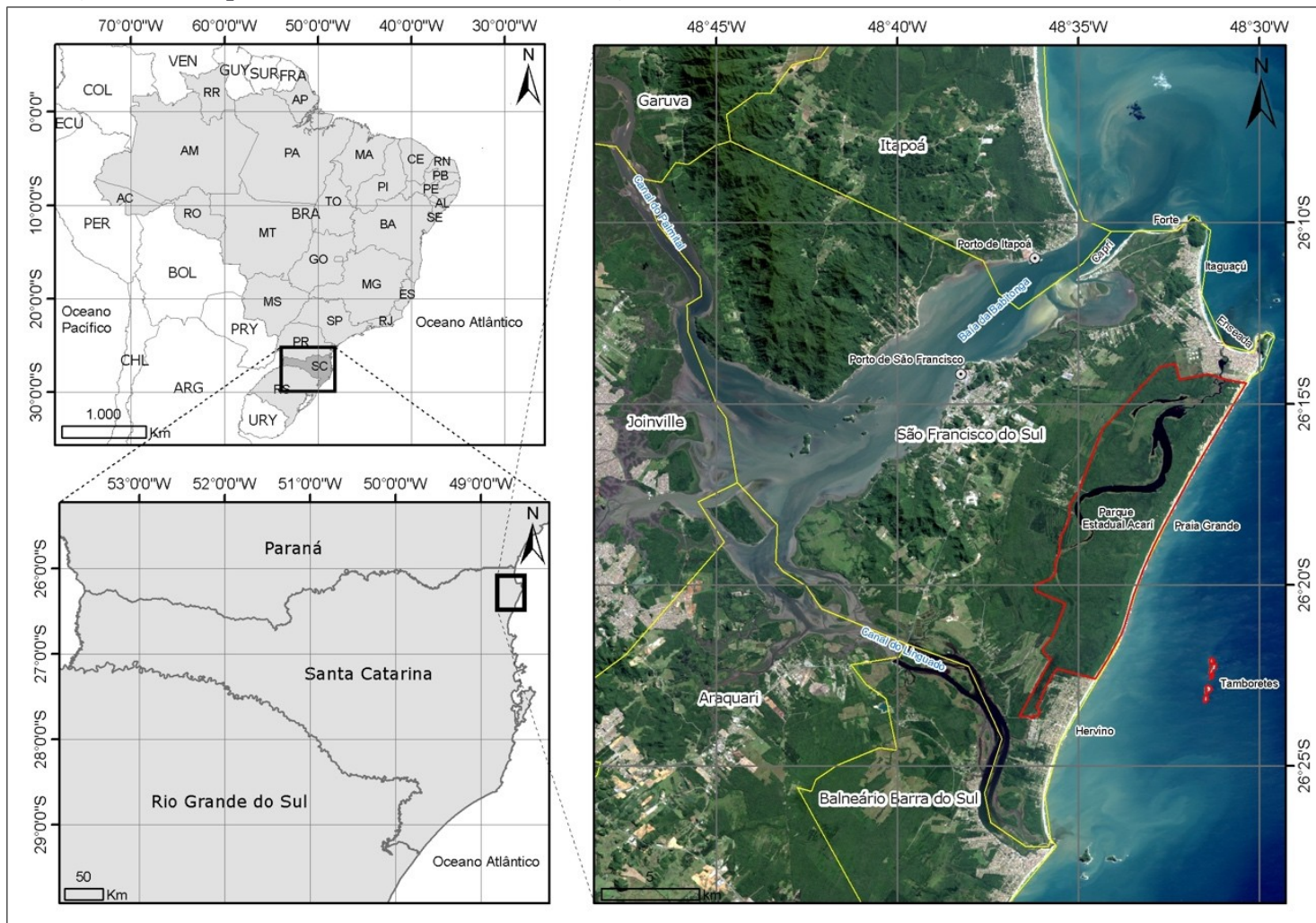

Figura 1 - Localização do município de São Francisco do Sul.

A Baía Babitonga é margeada por vegetação nativa típica de manguezais, que correspondem a 75\% do total deste ecossistema no estado de Santa Catarina, com uma área aproximada de 6.200ha (Ibama, 1998). Em 2003, o Projeto de Conservação e Utilização Sustentável da Diversidade Biológica Brasileira
-PROBIO, identificou as áreas de entorno da Baía Babitonga como Áreas Prioritárias para Conservação, Utilização e Repartição de Benefícios da Biodiversidade Brasileira, estando classificadas com prioridade Extremamente Alta e para as quais 
recomendava-se o manejo e a criação de Unidades de Conservação (PROBIO, 2003).

A despeito das inúmeras funções exercidas pelos manguezais, estas áreas vêm sofrendo intenso processo de destruição, com irreparáveis prejuízos ambientais, visto as dificuldades de recuperação de áreas degradadas e a importância deste ecossistema para a vida marinha, gerando a necessidade urgente de monitoramento (Rodrigues et al. 2005). O município de São Francisco do Sul detém grande parte de manguezal da baía da Babitonga e destaca-se devido a fragilidade ambiental destes ambientes, outrossim, reconhecido e protegido legalmente como Área de Preservação Permanente.

Destaca-se ainda a grande ocorrência de vegetação de restinga no município e a sua importância na manutenção de ambientes costeiros, como os esporões arenosos na praia do Capri (Cristofolini et al. 2017) e as dunas frontais na praia Grande (Alquini et al. 2017).

As Áreas de Preservação Permanente (APP) de acordo com a Lei Federal 12.651/12 em seu Art.3º, inciso II, podem ser entendidas como "área protegida, coberta ou não por vegetação nativa, com a função ambiental de preservar os recursos hídricos, a paisagem, a estabilidade geológica e a biodiversidade, facilitar o fluxo gênico de fauna e flora, proteger o solo e assegurar o bem-estar das populações humanas"
(BRASIL, 2012). A ocupação inadequada destas áreas pode acarretar diversos danos, bem como um desequilíbrio ambiental, uma vez que podem ser alteradas a composição dos solos, a fauna e flora, bem como os corpos hídricos que ficam sujeitos ao assoreamento e à contaminação das águas (Zanata et al. 2012).

Segundo Parizzi (2013), o total das áreas de restrições ambientais no município é de $151 \mathrm{~km}^{2}$. A unidade de conservação Estadual Parque Acaraí representa a maior parcela das áreas protegidas com $17,61 \%$ de representatividade no município. Seguido pelas APP's de recursos hídricos com $13,75 \%$ e pelas APP's de topo de morro, representando 6,98\%. Por fim, encontram-se as APP's de manguezal e de dunas, com $5,59 \%$ e $2,17 \%$, respectivamente.

\section{Metodologia}

Para a análise da evolução do uso e cobertura do solo foram obtidas imagens de média resolução espacial (30 m) disponibilizadas pelo Instituto Nacional de Pesquisas Espaciais (Inpe, 2016). Foram adquiridas três imagens orbitais que compreendem um período de 29 anos (1986 a 2015) compostas pelos sensores LANDSAT-5 e LANDSAT-8, com percentual de cobertura de nuvens inferior a $10 \%$, conforme descrito na Tabela 1.

Tabela 1 - Identificação das imagens orbitais e sensores utilizados.

\begin{tabular}{cccc}
\hline Data & Horário de Passagem & Sensor & Resolução Espacial \\
\hline $17 / 01 / 1986$ & $12: 38 \mathrm{~h}$ & LANDSAT-5 - TM & $30 \mathrm{~m}$ \\
\hline $31 / 05 / 2000$ & $12: 47 \mathrm{~h}$ & LANDSAT-5 - TM & $30 \mathrm{~m}$ \\
\hline $10 / 06 / 2015$ & $13: 10 \mathrm{~h}$ & LANDSAT-8 - OLI & $30 \mathrm{~m}$ \\
\hline
\end{tabular}

Fonte: INPE (2016).

$\mathrm{Na}$ Tabela 2 encontram-se descritas as bandas espectrais utilizadas para o processo de classificação das imagens orbitais, assim como o intervalo espectral das bandas dos sensores LANDSAT-5 e LANDSAT-8.

Todos os procedimentos de processamento digital de imagens (PDI) foram executados no ArcGIS 10.2.2 e envolveram o georreferenciamento, reprojeção, fusão de bandas (composição colorida), classificação supervisionada e a aplicação de filtros. $O$ georreferenciamento das imagens foi realizado tendo como base a restituição aerofotogramétrica em escala 1:10.000 do ano de 2010, disponibilizada pela SDS/SC. Todas as informações foram convertidas para a projeção UTM, datum SIRGAS2000, meridiano central W $51^{\circ}$ (fuso 22 sul).

Tabela 2 - Bandas espectrais dos sensores imageadores LANDSAT utilizadas no presente trabalho.

\begin{tabular}{ccc}
\hline \multirow{2}{*}{ Bandas } & \multicolumn{2}{c}{ Intervalo Espectral $(\boldsymbol{\mu m})$} \\
\cline { 2 - 3 } & LANDSAT-5 TM & LANDSAT-8 OLI \\
\hline 1 & $0,45-0,52($ azul $)$ & $0,43-0,45($ azul costeiro $)$ \\
\hline 2 & $0,52-0,60$ (verde) & $0,45-0,51$ (azul) \\
\hline 3 & $0,63-0,69$ (vermelho) & $0,53-0,59$ (verde) \\
\hline 4 & $0,76-0,90$ (IV próximo) & $0,64-0,67$ (vermelho) \\
\hline 5 & $1,55-1,75$ (IV médio) & $0,85-0,88$ (IV próximo) \\
\hline 6 & - & $1,57-1,65$ (IV ondas curtas) \\
\hline 7 & $2,08-2,35$ (IV médio) & $2,11-2,29$ (IV ondas curtas) \\
\hline
\end{tabular}

Fonte: USGS (2016).

Posteriormente foram realizadas as fusões entre bandas espectrais dos sensores imageadores com o objetivo de criar composições coloridas para a identificação das classes de uso e cobertura do solo. A composição colorida adotada para a classificação das imagens foi a falsa cor, compostas pelas as bandas 543 para o sensor LANDSAT-5 TM e as bandas 764 para o sensor LANDSAT-8 OLI. A composição falsa cor 
permite realçar o contraste entre a vegetação, corpos d'água, áreas úmidas, áreas urbanizadas e solo exposto (GOFC-GOLD, 2017).

Foi adotado o processo de classificação pixel a pixel com o método de classificação supervisionada. O processo consiste em treinar o algoritmo para poder distinguir distintas classes de uso do solo, em função do comportamento espectral dos alvos. O treinamento supervisionado é controlado de perto pelo analista. Nesse processo o analista escolhe pequenas áreas de amostras na imagem, contendo poucas centenas de pixels que sejam bem representativos espectralmente, de padrões ou feições dos alvos por ele reconhecidos, ou que podem ser identificados com a ajuda de outras fontes, tais como dados coletados no campo ou de mapas (Menezes \& Almeida, 2012).

Desta maneira, para o município de São Francisco do Sul foram definidas oito classes de amostragem, selecionadas de acordo com as características naturais e antrópicas predominantes no município. As classes definidas foram: água, manguezal, área urbanizada, vegetação em estágio médio/avançado, vegetação em estágio inicial, solo exposto, gramínea e silvicultura.

Para a classificação das imagens foi adotado o classificador por máxima verossimilhança (MaxVer). De acordo com Menezes \& Almeida (2012) este classificador MaxVer considera a ponderação das distâncias entre as médias dos valores dos pixels das classes utilizando parâmetros estatísticos. O classificador MaxVer assume que todas as bandas têm distribuição normal e calcula a probabilidade de um dado pixel pertencer a uma classe específica (Inpe, 2008). É um classificador eficiente porque as classes de treinamento são utilizadas para estimar a forma da distribuição dos pixels contidos em cada classe no espaço de $\mathrm{n}$ bandas (Menezes \& Almeida, 2012)

Posteriormente foi utilizado o filtro majority filter, com o objetivo de corrigir e filtrar pixels isolados e tornar a imagem classificada mais contígua, visto as eventuais inconsistências probabilísticas no processo de classificação. Neste método cada pixel é analisado considerando oito pixels vizinhos como janela de pesquisa, sendo que pelo menos quatro pixels da mesma classe devem existir para que ocorra a alteração do valor de classe do pixel analisado (Esri, 2016). Ressalta-se que quando verificados equívocos na classificação, foram realizadas correções manuais pelo analista, como na seleção de polígonos que não correspondiam à classe identificada, convertendo-os em suas classes corretas.

As áreas de restrição ambiental no município compreenderam as Áreas de Preservação Permanente (APP) definidas pela Lei Federal $\mathrm{n}^{\circ}$. 12.651/12 (BRASIL, 2012), Art. $4^{\circ}$ e a unidade de conservação de proteção integral do Parque Estadual Acaraí (Decreto Estadual no. 3.517/05). Para a delimitação das APP's no município de São Francisco do Sul/SC foi adotado o mapeamento proposto por Parizzi (2013) e o limite da Unidade de Conservação foi adquirido junto ao Ministério do Meio Ambiente (MMA, 2016).

Por fim, foram realizadas duas análises espaciais: (i) evolução do uso e cobertura do solo do município de São Francisco do Sul/SC; (ii) evolução do uso e cobertura do solo nas áreas de restrição ambiental.

\section{Resultados e discussões}

\subsection{Classificação de uso e cobertura do solo no Município de São Francisco do Sul}

Com relação ao método de classificação supervisionada pixel a pixel empregado na área de estudo, pode-se julgar que a utilização da metodologia permitiu a correta classificação de $90 \%$ da área do município. Todavia, ressaltam-se como limitações do método a incoerência na classificação de pixels isolados e a influência do relevo na determinação De algumas classes, que demandou intervenções pontuais do analista na classificação.

As alterações na dinâmica de uso e cobertura do solo do município de São Francisco do Sul são apresentadas na Tabela 3 e na Figura 2.

Os resultados das classificações de uso e cobertura do solo realizadas para os anos de 1986, 2000 e 2015 podem ser visualizados no webgis criado para a publicação dos mapas temáticos (https://www.arcgis.com/apps/Styler/index.html? appid $=787 \mathrm{bc} 40 \mathrm{fed} 5 \mathrm{c} 4 \mathrm{a} 4 \mathrm{fad} 337 \mathrm{fc} 1 \mathrm{~cd} 14 \mathrm{c} 7 \mathrm{ac}), \quad$ assim como, nas figuras 3,4 e 5, respectivamente.

Tabela 3 - Resultados das classificações de uso e cobertura do solo.

\begin{tabular}{|c|c|c|c|c|c|c|}
\hline \multirow[b]{2}{*}{ Classes } & \multicolumn{2}{|c|}{1986} & \multicolumn{2}{|c|}{2000} & \multicolumn{2}{|c|}{2015} \\
\hline & $\begin{array}{c}\text { Área total } \\
\left(\mathbf{k m}^{2}\right)\end{array}$ & $\begin{array}{l}\text { Área total } \\
(\%)\end{array}$ & $\begin{array}{c}\text { Área total } \\
\left(\mathbf{k m}^{2}\right)\end{array}$ & $\begin{array}{c}\text { Área total } \\
(\%)\end{array}$ & $\begin{array}{c}\text { Área total } \\
\left(\mathbf{k m}^{2}\right)\end{array}$ & $\begin{array}{l}\text { Área total } \\
(\%)\end{array}$ \\
\hline Água & 115,28 & 23,28 & 114,42 & 23,11 & 114,77 & 23,18 \\
\hline Manguezal & 17,52 & 3,54 & 20,60 & 4,16 & 23,27 & 4,70 \\
\hline $\begin{array}{l}\text { Vegetação em } \\
\text { estágio } \\
\text { médio/avançado }\end{array}$ & 255,31 & 51,57 & 265,91 & 53,71 & 251,16 & 50,73 \\
\hline $\begin{array}{l}\text { Vegetação em } \\
\text { estágio inicial }\end{array}$ & 8,12 & 1,64 & 3,21 & 0,65 & 46,36 & 9,36 \\
\hline Gramíneas & 43,04 & 8,69 & 25,80 & 5,21 & 10,54 & 2,13 \\
\hline Silvicultura & 17,32 & 3,50 & 10,31 & 2,08 & 6,79 & 1,17 \\
\hline Solo exposto & 19,81 & 4,00 & 31,84 & 6,43 & 9,18 & 1,86 \\
\hline Área urbanizada & 18,69 & 3,77 & 23,00 & 4,65 & 34,03 & 6,87 \\
\hline
\end{tabular}


As pequenas oscilações observadas na classe água podem ser interpretadas como decorrência das diferenças sazonais de precipitação e oscilações dos níveis de maré, quando da obtenção das imagens. As oscilações representam uma redução de $0,86 \mathrm{~km}^{2}$, entre os anos de 1986 e 2000 e um aumento de $0,35 \mathrm{~km}^{2}$ entre o ano 2000 e 2015.

As áreas classificadas como manguezal apresentaram um aumento contínuo ao longo do período estudado $\left(5,57 \mathrm{~km}^{2}\right.$ no total). $\mathrm{O}$ incremento de área de manguezal representa um aspecto positivo de manutenção do ecossistema, entendido como uma minimização de intervenção antrópica direta no ambiente, como supressão de vegetação e aterro. Entretanto, deve ser ressaltada a possibilidade do processo dinâmico de assoreamento da baía da Babitonga, fato que pode ter contribuído com o avanço do manguezal sobre as áreas de bancos e baixios. Vieira \& Horn Filho (2017) em estudo sobre a paisagem marinha da baía da Babitonga relataram que a profundidade média da baía é de apenas $3,5 \mathrm{~m}$ e as estruturas de paisagem de maior ocorrência referem-se a planície rasa e crista sobre banco, corroborando a dinâmica observada no presente estudo.

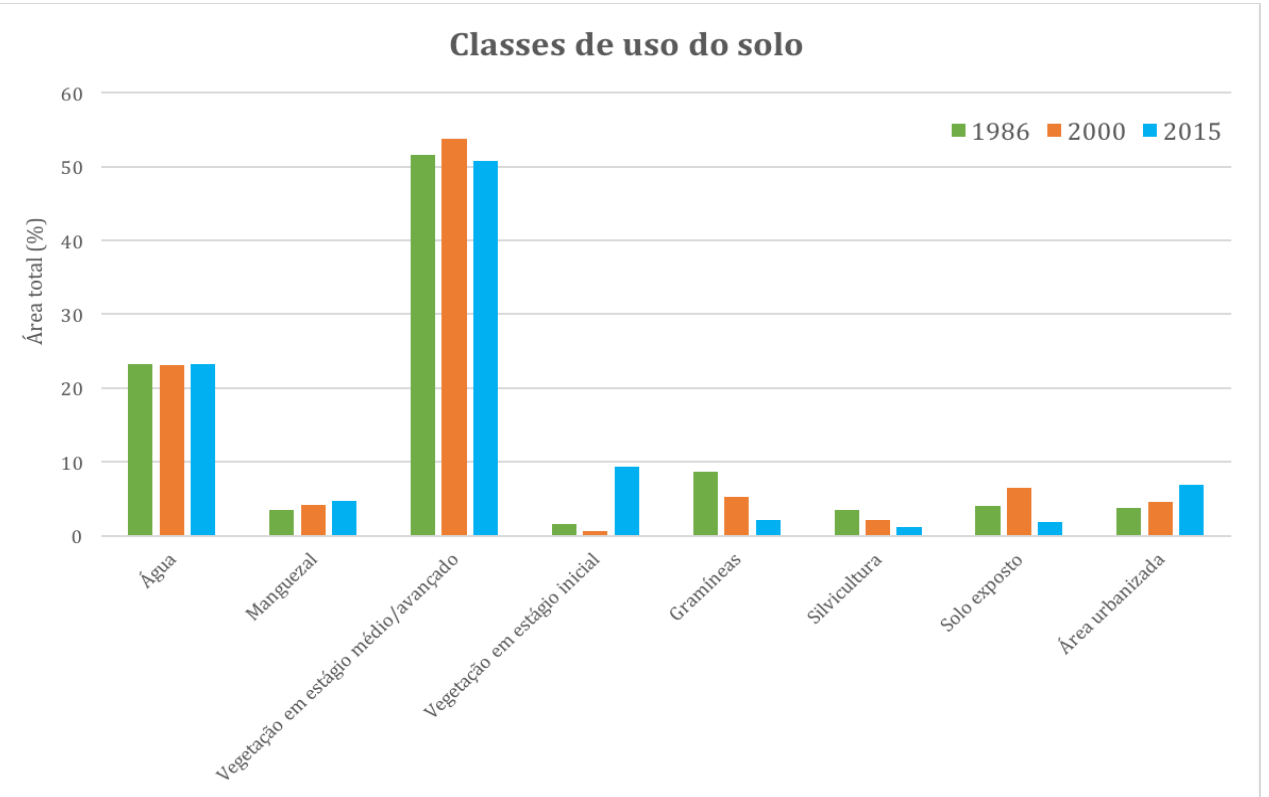

Figura 2 - Gráfico comparativo das classes de uso do solo para os anos de 1986, 2000 e 2015.

Em relação a classe de vegetação em estágio médio/avançado observa-se que não ocorreram variações significativas durante o período analisado, com $2,14 \%$ entre os anos de 1986 e 2000 e $2,98 \%$ entre 2000 e 2015. Este fato evidencia uma relativa preservação da Floresta Ombrófila Densa e de Restinga.

A classe de silvicultura sofreu uma grande redução de área na ordem de 1.053 ha $\left(10,53 \mathrm{~km}^{2}\right)$ do ano de 1986 a 2015, que representa um decréscimo de 61\%. Essa redução contínua das atividades de silvicultura no município de São Francisco do Sul, podem estar relacionadas com a implantação de unidades de conservação e o efetivo cumprimento da legislação ambiental vigente.

Os dados de solo exposto apresentam um crescimento entre o período do ano de 1986 a 2000 (Figuras 3 e 4) evidenciando o aumento das atividades de supressão de vegetação neste período, com uma área de $12,03 \mathrm{~km}^{2}$. Esta classe diminuiu consideravelmente no ano de 2015 quando comparada à imagem de 2000 . Ressalta-se que as áreas de solo exposto foram convertidas, primeiramente, nas classes de gramíneas e posteriormente, em vegetação em estágio inicial, caracterizando assim o processo de regeneração da vegetação nativa. Este processo torna-se mais evidente quando se observa a classe de gramíneas apresentando um declínio em área ocupada, de 43,04 km² em 1986 para 10,04 km² em 2015.

Comparando as Figuras 3, 4 e 5 observa-se uma tendência de áreas classificadas como gramíneas em 1986 que foram convertidas nos anos de 2000 e 2015 em vegetação em estágio inicial e posteriormente em vegetação em estágio médio avançado.

$\mathrm{O}$ resultado obtido na classificação indica um sucessivo e nítido crescimento das áreas urbanizadas no município, com um aumento de 15,34 km² de 1986 a 2015. Entre o período de 1986 a 2000, este crescimento foi mais significativo no centro e no balneário norte do município. Já no período entre os anos de 2000 a 2015 o crescimento das áreas urbanizadas ocorreu de maneira mais intensa na praia do Ervino, no sul do município (Figuras 4 e 5). 


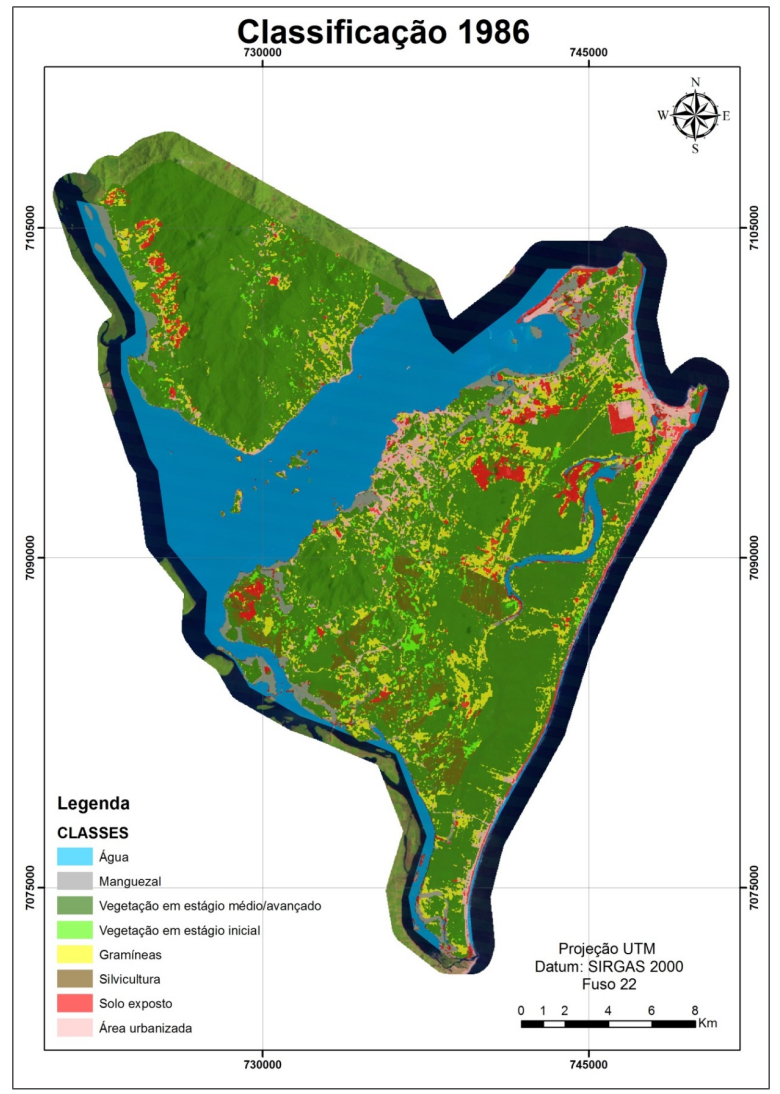

Figura 3 - Classificação de uso e cobertura do solo em 1986.

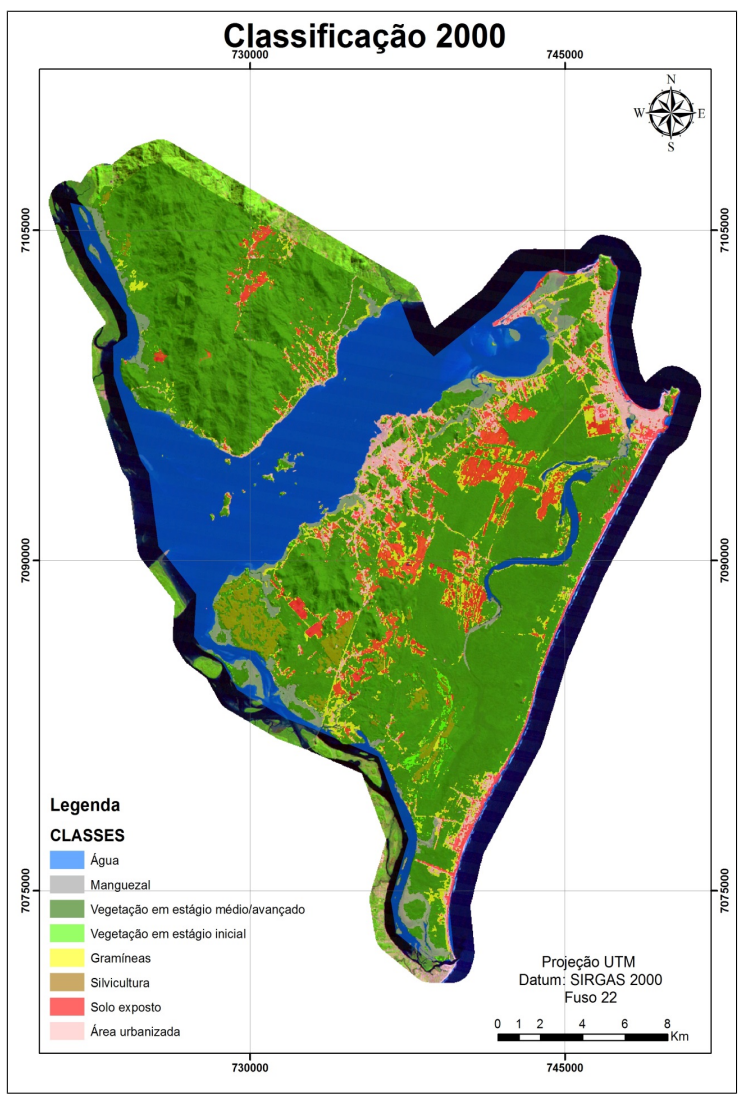

Figura 4 - Classificação de uso e cobertura do solo em 2000.

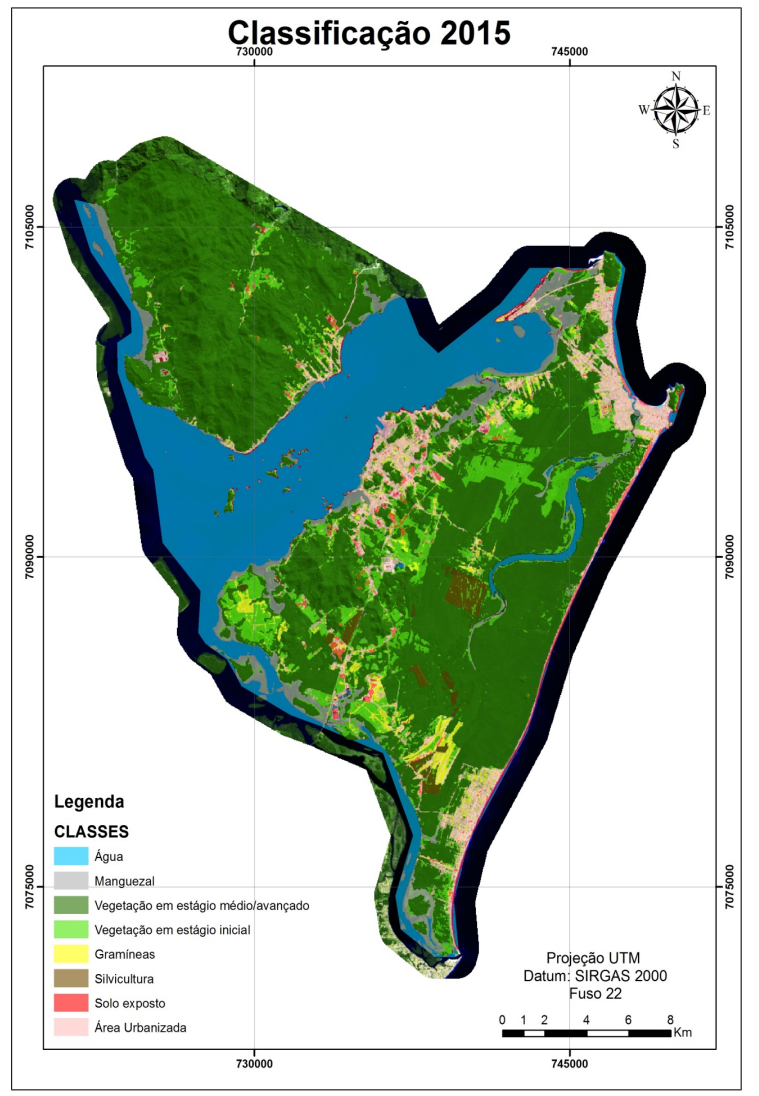

Figura 5 - Classificação de uso e cobertura do solo em 2015.

Segundo o IBGE (2017), a expansão da área urbana no município de São Francisco do Sul está diretamente relacionada ao crescimento populacional do município e ao aumento de casas de veraneio. O crescimento populacional no período de 1990 a 2000 foi de 2,9 mil habitantes, enquanto que no período de 2000 a 2010 o crescimento foi substancialmente mais elevado, na ordem de 10,2 mil habitantes. Aliando esse aumento à estimativa populacional de 49.658 mil habitantes em 2016 (IBGE, 2017) é possível verificar que o incremento da área urbana ocorreu de maneira proporcional. A ocupação das terras sem planejamento e através de usos múltiplos indica a complexidade, dificuldade e a necessidade da elaboração de propostas para a gestão territorial (Pinto \& Garcia, 2005). Cabe ressaltar ainda, que a expansão das áreas urbanizadas do município ocorreu, em sua maioria, em detrimento de áreas que eram ocupadas por vegetação em estágio médio/avançado, comprometendo os recursos genéticos e a biodiversidade dos ecossistemas naturais do município.

\subsection{Classificação de uso e cobertura do solo nas áreas de restrição ambiental}

As classificações de uso e cobertura do solo nas áreas de restrição ambiental são apresentadas na Figura 6, assim como no webgis (https://www.arcgis.com/apps/Styler/index.html? appid $=787 \mathrm{bc} 40 \mathrm{fed} 5 \mathrm{c} 4 \mathrm{a} 4 \mathrm{fad} 337 \mathrm{fc} 1 \mathrm{~cd} 14 \mathrm{c} 7 \mathrm{ac})$. 
Os resultados das classificações de uso e cobertura do solo nas áreas restrição ambiental para os anos de 1986, 2000 e 2015 são apresentados na Tabela 4.

A classe água nas áreas de restrição ambiental, assim como na classificação total do munícipio, igualmente apresenta pequenas oscilações. Estas podem ser interpretadas como decorrência das diferenças sazonais de precipitação e oscilações dos níveis de maré quando da obtenção das imagens.

Os manguezais representam atualmente cerca de $10 \%$ da área total das áreas de restrições ambientais, ocorrendo um crescimento contínuo desta classe nos períodos analisados. Esta tendência indica uma diminuição da pressão antrópica que possibilitou a regeneração destes ambientes.

As áreas de solo exposto aumentaram $1,28 \mathrm{~km}^{2}$ no período entre os anos de 1986 a 2000. Contudo, entre o período de 2000 a 2015 a classe de solo exposto sofreu uma expressiva redução de área, na ordem de $6,47 \mathrm{~km}^{2}$ (647 ha) (Figura 6). Ao longo do período estudado (1986 a 2015) observou-se que estas áreas foram convertidas em gramínea e posteriormente em vegetação em estágio inicial, evidenciando uma fase de regeneração natural destas áreas. Essa tendência pode ser ratificada pela diminuição de área da classe gramínea, na ordem de $13 \mathrm{~km}^{2}$ e o aumento da classe vegetação em estágio inicial em $10,97 \mathrm{~km}^{2}$ durante o período analisado (Figura 6).

Observou-se também uma importante dinâmica nas áreas de silvicultura com o crescente abandono da citada atividade em áreas de APP e no interior do Parque Estadual Acaraí. As áreas de silvicultura durante o período analisado (1986 a 2015) sofreram uma diminuição na ordem de $1,54 \mathrm{~km}^{2}$ (154 ha) com a crescente substituição por vegetação em estágio inicial.

Destacam-se também, as transformações de uso e cobertura do solo ocorridas no interior do Parque Estadual Acaraí, criado em 2005 (FATMA, 2006). Nos anos de 1986 e 2000 ocorriam extensas áreas de solo exposto e gramíneas, que deram origem a áreas com vegetação em estágio inicial e vegetação em estágio médio/avançado no ano de 2015. As constatações da alteração nas classes de uso e ocupação do solo indicam a regeneração natural, anteriormente descrita e a importância da unidade de conservação de proteção integral na manutenção de extensas áreas vegetadas no município.

Quanto às áreas urbanizadas, pode-se observar um aumento contínuo ao longo do período estudado, passando de 2,70 $\mathrm{km}^{2}$ em 1986, para 4,41 $\mathrm{km}^{2}$ em 2015. Esta ocupação irregular foi observada mais significativamente ao longo de APP's de cursos d'água.

Todavia, quando analisadas as classes naturais, composta por água, manguezal, vegetação em estágio médio/avançado e vegetação em estágio inicial, observou-se um aumento contínuo no somatório dessas classes ao longo do período em estudo (Figuras 6 e 7). Já as classes antrópicas, composta por gramíneas, silvicultura, solo exposto e área urbanizada, foi observado um declínio contínuo e considerável nos anos de 2000 e 2015, quando comparados a 1986, conforme pode ser observado nas figuras 6 e 7 .

Cabe ressaltar que as classes de uso e cobertura do solo entendidas como naturais, representavam em 2015 um total de 94,6\% das áreas de restrição ambiental do município e, em 1986 eram de 82,7\%. Isso representa um acréscimo de $11,9 \%$ de áreas regeneradas. A classe natural que apresentou o crescimento mais significativo foi a vegetação em estágio inicial, com um incremento de $10,97 \mathrm{~km}^{2}$ de 1986 para 2015 . Seguida pelas classes manguezal e vegetação em estágio médio/avançado, com um acréscimo de $3,9 \mathrm{~km}^{2}$ e $3,41 \mathrm{~km}^{2}$, respectivamente, para este mesmo período. O Parque Estadual Acaraí foi o local onde melhor se observou esta regeneração natural, principalmente no período entre o ano 2000 a 2015 , devido à sua criação em 2005. Tabela 4 - Resultado da classificação de uso e cobertura do solo nas áreas de restrições ambientais.

\begin{tabular}{cccccccc}
\hline & \multicolumn{2}{c}{$\mathbf{1 9 8 6}$} & \multicolumn{2}{c}{$\mathbf{2 0 0 0}$} & \multicolumn{2}{c}{$\mathbf{2 0 1 5}$} \\
\cline { 2 - 8 } Classes de uso e cobertura & $\begin{array}{c}\text { Área total } \\
\left(\mathrm{km}^{2}\right)\end{array}$ & $\begin{array}{c}\text { Área total } \\
(\%)\end{array}$ & $\begin{array}{c}\text { Área total } \\
\left(\mathrm{km}^{2}\right)\end{array}$ & $\begin{array}{c}\text { Área total } \\
(\%)\end{array}$ & $\begin{array}{c}\text { Área total } \\
\left(\mathrm{km}^{2}\right)\end{array}$ & $\begin{array}{c}\text { Área total } \\
(\%)\end{array}$ \\
\hline Água & 3,88 & 2,56 & 3,96 & 2,62 & 3,64 & 2,41 \\
\hline & 12,22 & 8,08 & 14,37 & 9,50 & 16,12 & 10,66 \\
\hline $\begin{array}{c}\text { Manguezal } \\
\text { Vegetação em estágio } \\
\text { médio/avançado }\end{array}$ & 106,88 & 70,69 & 111,33 & 73,62 & 110,29 & 72,93 \\
\hline $\begin{array}{c}\text { Vegetação em estágio } \\
\text { inicial }\end{array}$ & 2,07 & 1,37 & 0,64 & 0,42 & 13,04 & 8,62 \\
\hline Gramíneas & 13,96 & 9,23 & 8,05 & 5,32 & 0,96 & 0,64 \\
\hline Silvicultura & 2,19 & 1,45 & 0,91 & 0,60 & 0,65 & 0,43 \\
\hline Solo exposto & 7,30 & 4,83 & 8,58 & 5,67 & 2,11 & 1,40 \\
\hline Área urbanizada & 2,70 & 1,78 & 3,39 & 2,24 & 4,41 & 2,92 \\
\hline
\end{tabular}




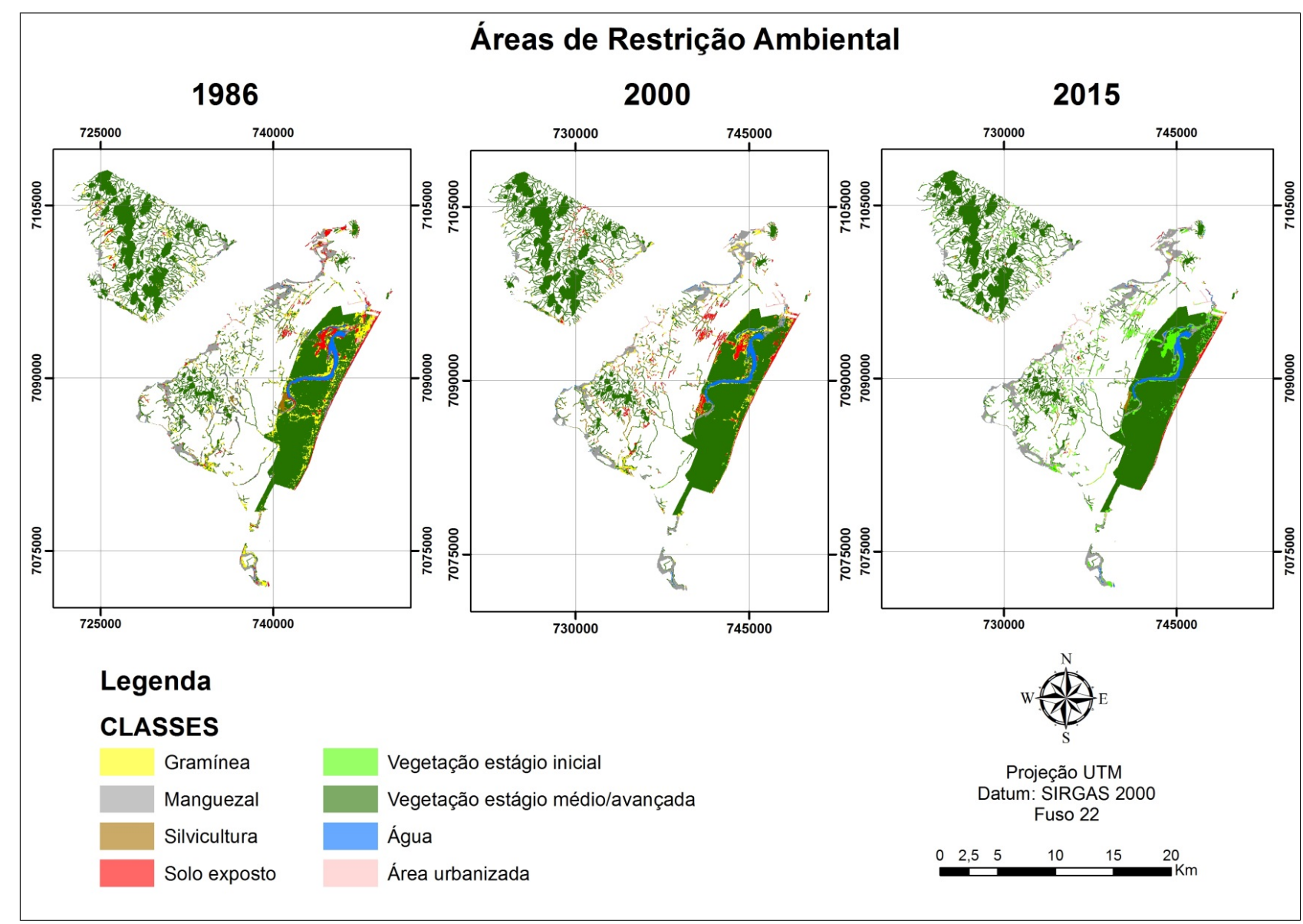

Figura 6- Classificações de uso e cobertura do solo nas áreas de preservação permanente.

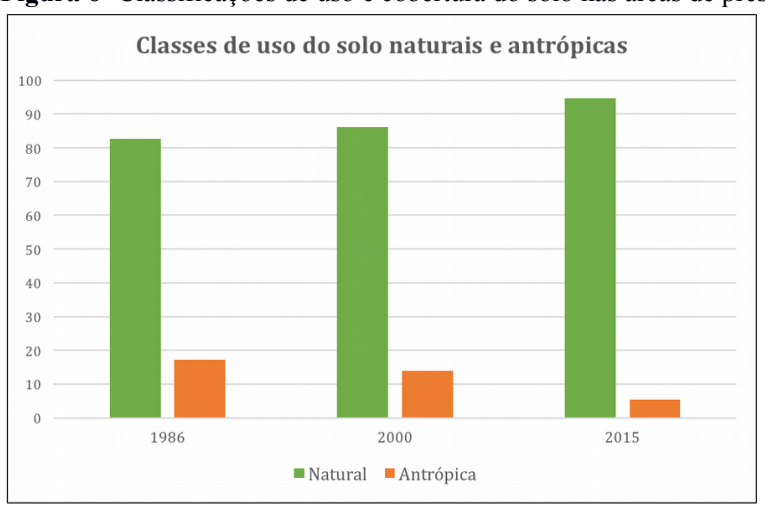

Figura 7- Classificação do uso e cobertura do solo em áreas de restrições ambientais.

\section{Considerações finais}

Com a realização do presente trabalho, pode-se concluir que os sensores remotos e as ferramentas SIG's são de suma importância para a classificação do uso e cobertura do solo em municípios, bem como, se tornam essenciais para o planejamento e gestão dos recursos naturais.

Pode-se concluir também, que a imagem do satélite LANDSAT-8 proporcionou uma melhor classificação de uso e cobertura do solo, quando comparada com as imagens do satélite LANDSAT-5, em função da melhor resolução espectral do sensor OLI (Operacional Land Imager). Destaca-se ainda a agilidade e simplicidade no uso desses dados do
LANDSAT-8, uma vez que a correção geométrica já vem implementada (NASA, 2017), diferente das imagens do satélite LANDSAT-5, que necessita desta correção.

$\mathrm{Na}$ classificação de uso e cobertura do solo, das imagens de 1986, 2000 e 2015, observou-se um aumento gradual e considerável nas áreas urbanizadas do município, com 15,37 $\mathrm{km}^{2}$. Quanto à classe solo exposto, esta apresentou um crescimento significativo entre 1986 e 2000, associado principalmente ao corte raso promovido nas áreas de silvicultura. Em 2015 esta classe diminuiu de forma expressiva, quando comparada aos anos de 2000 e 1986, com um grande desenvolvimento de vegetação em estágio inicial.

$\mathrm{O}$ estudo demonstrou uma regeneração das áreas degradadas detectado pela conversão temporal das áreas de solo exposto em áreas de gramíneas e destas em vegetação em estagio inicial. A regeneração natural ocorreu também nas áreas degradadas no Parque Acaraí e nas áreas de silvicultura que foram significativamente extintas.

Nas áreas entendidas como de restrição ambiental as classes de uso do solo classificada como naturais sofreram um aumento contínuo ao longo do período estudado, comprovando assim a regeneração natural em APP's e no Parque Acaraí. O local onde melhor se observou a regeneração natural foi no Parque Acaraí, principalmente entre o ano 2000 de 2015, devido sua criação em 2005. 


\section{Referências bibliográficas}

ALQUINI, F.; SARTI, G.; CICCARELLI, D; MELO JR, J. C. F.; VIEIRA, C. V. 2017. Vulnerabilidade costeira do ambiente de restinga. In: MELO JÚNIOR, J. C. F.; BOEGER, M. R. T. (eds) Patrimonio natural, cultura e biodiversidade da restinga do Parque Estadual Acaraí. Joinville, Editora Univille, 385-411p.

AMARAL M.B, RIOS S.A. 2012. Geoprocessamento: mapeamento do uso e ocupação do solo no alto curso do Rio Piedade. Revista de geografia física, 2:1-8.

BRASIL. Lei Federal 12.651 de 25 de maio de 2012. Dispõe sobre a proteção da vegetação nativa. Disponível em: http://www.planalto.gov.br/ccivil_03/_ato2011-

2014/2012/lei/L12651 compilado.htm. Acessado em 25 julho 2017.

CRISTOFOLINI, J., VIEIRA, C.V., MELO JR, J.C.F. 2017. Relationship between the sand spit geomorphology and restinga vegetation in São Francisco do Sul island, south region of Brazil. Journal of Development Research, 7(6):13314-13321.

ENVIRONMENTAL SYSTEMS RESEARCH INSTITUTE - ESRI. 2016. Majority Filter. Disponível em: $<$ http://desktop.arcgis.com/en/arcmap/10.3/tools/spatial-analysttoolbox/majority-filter.htm> Acessado em 25 setembro 2016.

FUNDAÇÃO DO MEIO AMBIENTE - FATMA. 2016. Parque Estadual Acaraí. Disponível em: $<\mathrm{http} / / /$ www.fatma.sc.gov.br/conteudo/parque-estadual-acarai $>$ Acessado em 16 novembro 2016.

GLOBAL OBSERVATION FOR FOREST COVER AND LAND DYNAMICS - GOFC-GOLD. A Sourcebook of Methods and Procedures for Monitoring Essential Biodiversity Variables in Tropical Forests with Remote Sensing. The Netherlands : CGOLD Land Cover Project Office, 2017. Disponível em: http://www.gofcgold.wur.n1/sites/gofcgold-

geobon_biodiversitysourcebook.php. Acessado dia 15 julho 2017.

INSTITUTO BRASILEIRO DE GEOGRAFIA E ESTATÍSTICA IBGE. 2013. Manual técnico de uso da terra. Rio de Janeiro, IBGE, $\quad 171 \mathrm{p} . \quad$ Disponível em: < http://biblioteca.ibge.gov.br/visualizacao/livros/liv81615.pdf>. Acessado dia 15 novembro 2016.

INSTITUTO BRASILEIRO DE GEOGRAFIA E ESTATÍSTICA IBGE. 2017. Cidades. Disponível em: < https://cidades.ibge.gov.br/v4/brasil/sc/sao-francisco-dosul/panorama $>$. Acessado dia 15 jul. 2017.

INSTITUTO BRASILEIRO DO MEIO AMBIENTE E DOS RECURSOS NATURAIS RENOVÁVEIS - IBAMA. 1998. Proteção e controle de ecossistemas costeiros: manguezais da Baía de Babitonga. Brasília, IBAMA, 146p.

INSTITUTO DO PATRIMÔNIO HISTÓRICO ARTÍSTICO NACIONAL - IPHAN. 2016. São Francisco do Sul (SC). Disponível em: $<$ http://portal.iphan.gov.br/pagina/detalhes/398/> Acessado dia 11 outubro 2016.

INSTITUTO NACIONAL DE PESQUISAS ESPACIAIS - INPE. 2008. Manuais: tutorial de geoprocessamento SPRING. Disponível

$<$ http://www.dpi.inpe.br/spring/portugues/tutorial/> Acessado dia 14 novembro 2016.

INSTITUTO NACIONAL DE PESQUISAS ESPACIAIS. - INPE. 2016. Catálogo de Imagens. Disponível em: $<$ http://www.dgi.inpe.br/CDSR/>. Acessado dia 03 abril 2016.

MENEZES P.R., ALMEIDA T. 2012. Introdução ao Processamento de Imagens de Sensoriamento Remoto. Brasília, UNB/CNPQ, 276 p.

MINISTÉRIO DO MEIO AMBIENTE - MMA. 2016. Download de dados geográficos. Disponível em:
$<$ http://mapas.mma.gov.br/i3geo/datadownload.htm>. Acessado dia 25 setembro 2016.

NATIONAL AERONAUTICS AND SPACE ADMINISTRATION NASA. Landsat Data Continuity Mission: Continuously Observing Your World. 2017. Disponível em: $<$ http://ldcm.gsfc.nasa.gov/mission_details.html>. Acessado dia 19 julho 2017.

PARIZZI L.C. 2013. Delimitação das Áreas de Preservação Permanente do município de São Francisco Do Sul - Santa Catarina. Trabalho de Conclusão de Curso. Graduação em Engenharia Ambiental, Universidade da Região de Joinville, $15 \mathrm{p}$.

PINTO S.A.F., GARCIA G.J. 2005. Experiências de aplicação de geotecnologias e modelos na análise de bacias hidrográficas. Revista do Departamento de Geografia, 17:30-37.

PROJETO DE CONSERVAÇÃO E UTILIZAÇ̃̃O SUSTENTÁVEL DA DIVERSIDADE BIOLÓGICA BRASILEIRA - PROBIO. 2007. Áreas Prioritárias Para a Conservação, Utilização Sustentável e Repartição de Benefícios da Biodiversidade Brasileira. MMA/SBF, Brasília, 301p. Disponível em:

http://www.mma.gov.br/estruturas/chm/_arquivos/biodiversidad e31.pdf>. Acessado dia 04 setembro 2016.

RODRIGUES A.M.T, ANDRADE A.B, FERREIRA E.C, GONCHOROSKY J, GERHARDINGER L, BRITTO M.K, CREMER M.J, HOSTIM M. 2005. Reserva da Babitonga. Disponível

$<\mathrm{http}$ ://solamac.org/babitonga/babitonga_prop_final.pdf $>$ Acesso em 16 abr. 2016.

RODRIGUES A.M.T., BRANCO E.J., SACCARDO S.A., BLANKESTEYN, A. A. 2000. Explotação do caranguejo-uçá Ucides cordatus (Decapoda: Ocypodidae) e o Processo de Gestão Participativa para a Normalização da Atividade na Região Sudeste-Sul do Brasil. Boletim do Instituto de Pesca, 26(1): 63-78.

ROSA, R. 2009. Introdução ao sensoriamento remoto. EDUFU, Uberlândia, 136p.

SIMÃO P., MORAES A. 2009. Mapeamento de Uso e Ocupação do Solo. Disponível em: $<$ http://mundogeo.com/blog/2009/07/09/mapeamento-de-uso-eocupacao-do-solo/>. Acessado dia 20 abril 2016.

UNITED STATES GEOLOGICAL SURVEY - USGS. 2016. Landsat Missions. Landsat Product Documentation. Disponível em: http://landsat.usgs.gov//tools_project_documents.php. Acessado dia 20 abril 2016.

VEIGA T.C., XAVIER-DA-SILVA, J. 2004. Geoprocessamento aplicado à identificação de áreas potenciais para atividades turísticas: o caso do município de Macaé - RJ. In: XAVIER-DA SILVA J., ZAIDANR T. (eds) Geoprocessamento e análise ambiental: aplicações. Bertrand Brasil, Rio de Janeiro, 179215p.

VIEIRA, C.V., HORN FILHO, N.O. 2017. Paisagem marinha da baía da Babitonga, nordeste de Santa Catarina. Revista Brasileira de Geografia Física, 10(5):1677-1689.

ZANATA J.M., PIROLI E.L., DELATORRE C.C.M., GIMENES G.R. 2012. Análise do uso e ocupação do solo nas áreas de preservação permanente da microbacia ribeirão bonito, apoiada em técnicas de geoprocessamento. REVISTA GEONORTE, 2(4):1262-1272.
Manuscrito ID 50945

Submetido em fevereiro de 2017 Aceito em outubro de 2017 